MATEC Web of Conferences 44, 01045 (2016)

DOI: $10.1051 /$ matecconf $/ 20164401045$

(C) Owned by the authors, published by EDP Sciences, 2016

\title{
Design and Realization of Network Teaching System
}

\author{
Shan Shan $\mathrm{Ji}^{1}$ \\ Department of Computer Engineering, DongGuan Polytechnic, DongGuan GuangDong,523808, China
}

\begin{abstract}
Since 21 century, with the wide spread in family and public, network has been applied in many new fields, and the application in classes is of no exception. In traditional education, teachers give lessons to students face to face. Hence, the teaching quality depends largely on the quality and initiative of the individual teacher. However, the serious disadvantages of this mode are that teachers completely dominate the classroom and may ignore the subjective cognition role of the students, which may be bad for the growth of creativity and the innovative thinking ability. Obviously, traditional education mode cannot meet the requirements of the this new era which leads to the booming developing tendency of the network. As a new teaching measure, scientifically combining modern information technology and teaching practice, network teaching not only changes the traditional education by the means and form, but even also gives new meanings to teaching concept, process, method as well as teacher-student role and other deep levels. With the help of network teaching system, on-line classroom learning, relevant information systematization, standardization and automation, this system provides students with an efficient online learning method with high quality. This also helps to solve the disadvantages of the traditional teaching mode and promote the teaching methods to a new stage. It improves the network teaching platform, enriches the network teaching resources, and establishes a network teaching system, so as to improve information quality of teachers and students and assist in improving teaching quality of schools.
\end{abstract}

\footnotetext{
${ }^{1}$ Author profile: Ji Shanshan (1985-), female, computer lecturer and network engineer in Dongguan Polytechnic, research direction: computer education Corresponding author: jss060@163.com
} 
In order to comprehensively implement the Scientific Outlook on Development and focus on quality improvement in developing higher education in an earnest manner, the Ministry of Education and the Ministry of Finance decide to implement quality engineering in universities and colleges. One of the requirements in implementing the quality engineering is to strengthen the excellent network resource construction of courses, take information technology as an important method to improve teaching quality, widely use information technology, change talent cultivation mode of universities and colleges, and constantly promote common construction and sharing of teaching resources, to gradually achieve the grand objective of networking and digitization of teaching and management.

From the current situation in China, the teaching mode in the 21 st century is basically teacher-centered. The advantages of this mode are that it is helpful for teachers to play the leading role and easy for teachers to organize and monitor the process of the whole teaching activity, which is convenient for emotion exchange between teachers and students, thus this mode is beneficial to systematically pass on scientific knowledge and it fully considers the important role of emotion factors in learning process. However, the serious disadvantages of this mode are that teachers completely dominate the classroom and ignore subjective cognition role of students, which is bad for growth of creative talent with innovative thinking and innovative ability.

Therefore, network teaching will certainly become a development trend in modern education. Network teaching system pays more attention to width, depth and effectiveness, achieving all-round integration of information technology and classroom. The basis of integration and application is to construct a perfect network teaching platform, while constructing a network teaching system with strong functions and good safety is the only way for network teaching, and it is also a fundamental method to solve the disadvantages in modern education.

\section{System Development Background}

The role of the teacher-centered teaching mode in the cause of education is indeed ineffaceable, but its serious disadvantages are that its basis in terms of learning theories is behaviorism. If this teaching mode dominates in the classrooms of various schools at all levels in China for a long term, the learning theories of behaviorism will have deep-rooted effects on the schools. As a new teaching form scientifically combining modern information technology and teaching practice, network teaching not only changes the traditional teaching from the means and form, but even also gives new meanings to teaching from concept, process, method, teacher-student role and other deep levels. All this originates from three basic characteristics of network teaching: creativity of teachers' labor, integration of knowledge information and cooperation of teaching processes. Thus, development of the network teaching system is just conforming to urgent hope of all the teachers and students.

\section{System Function Description}

Network teaching system is a system oriented to teachers and students, which takes students as core and provides humanized functions as much as possible, such as online teaching support system, network course development tools and online teaching resource management system. In this system, analysis and design of the system adopt UML as the modeling tool, using asp.net as the development platform, visual c\# as the programming language and sql as the database support. The system can adopt the object-oriented design and encapsulate database operations in categories, making program structure clear and easy to maintain. In the meantime, the system adopts a four-layer architecture where interface and business logic are separated, and encapsulates business logic in components, greatly improving safety, reliability, reusability and expansibility of the system.Functional requirements of network teaching system mainly include the followings:

(1) "Online class" function: teachers prepare courseware before class and store it on the server; students can enter corresponding "classroom" to watch the courseware to study (or download corresponding resources) This system adopts "asynchronous teaching mode": teachers provide online teaching courseware, students can carry out massed learning in online classrooms through the Internet, or separately carry out self-learning on demand with the teaching courseware on the computer, and communicate and discuss with teachers and students through the network. The schematic diagram of the online classroom is as shown in Figure 2.1: 


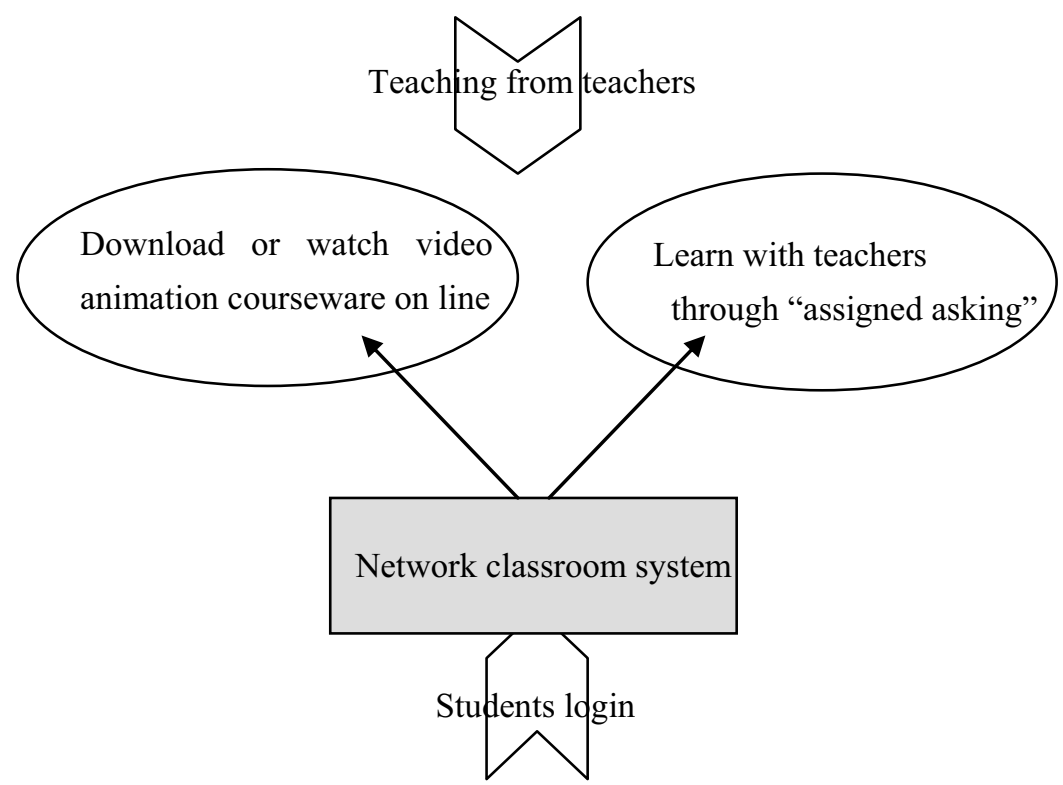

Figure 2.1 Schematic Diagram of "Online Class"

(2) "Raising hands to speak" function: this function is divided into two kinds: one is ordinary speak where students can express their thoughts, learning experience and others in the form of BBS, and the other is assigned asking where students can assign a teacher for asking questions which will be displayed on the "desktop" of the corresponding teacher.

(3) "Online signing up" function: students register a user name on line to $\log$ in the system; they can browse classrooms, and click "signing up" to submit the application to background, which will be seen by administrator.

(4) "My desk" function: personal information of students will be displayed on their own "my desk"; teachers can see "assigned asking" of the students on his/her "my desk"; students can see the "assigned answers" provided by the teachers on their own "my desk".

(5) E-business module: it handles sign-up sheet of students and opens classes; all the tuition revenue of the previous month and the current month are clear.
(6) Background management module: all the function parameters of the system can be configured; it manages the authorization of the users and user groups; it can manage each classroom and online courseware.

\section{System Objective}

The general task of developing this system is to achieve systematization, standardization and automation of various information related to online classroom learning. This system provides an efficient online learning method with high quality for students and solves disadvantages of the traditional teaching mode, promoting the teaching to a new stage. It improves the network teaching platform, enriches the network teaching resources, and establishes a network teaching system, so as to improve information quality of teachers and students and assist in improving teaching quality of schools.

\section{System Working Principle}

This system adopts a four-layer architecture design including database storage, database access, business logic and user interface, which are mutually independent. Its working principle is as shown in Figure 4.1: 
User Interface Layer

Business Logic Layer

Data Storage Layer

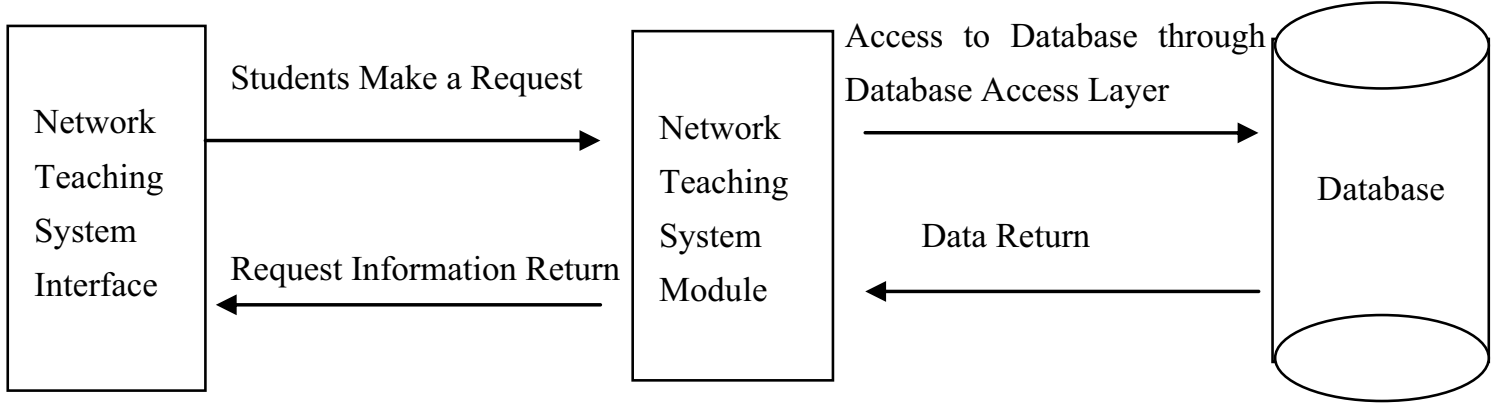

Figure 4.1 System Working Principle Diagram

The network teaching system has the following characteristics:

(1) Four-layer architecture design: this system adopts the four-layer architecture design, that is, the program logic structure is composed of user interface layer, business logic layer, database access layer and data storage layer. All the layers are mutually independent in the actual physical structure. The business logic is separated from the database access and the user interface is separated from the business logic, which greatly improves safety, maintainability, reusability and expansibility of the system.

(2) Object-oriented design: the system encapsulates the students and teachers into categories, and each category has its own corresponding collection class, thus improving the safety of the database operation and the expansibility of the program.

(3) More excellent stability: since $B / S$ is adopted, as long as your company has a browser (IE5.5 or above is recommended), you can use this system. $80 \%$ of the stability performance of the system on the client depends on the server performance, so it is unnecessary to consider the barrier set by the old $\mathrm{C} / \mathrm{S}$ installation method to the client performance.

(4) Faster speed: it adopts ASP.Net language $(\mathrm{CH})$, the newest product of Microsoft. If you have heard ASP, please don't say that ASP.Net is the updated version of ASP. As a matter of fact, ASP.NET and ASP are two completely different concepts, and their working principles are different. ASP only provides explanation of the server, while ASP.NET also has compiling function whose caching can greatly increase your access speed to the network.

\section{Conclusion}

Through test, we find that the system still has some imperfect problems, such as encoding test. These corrections need to be further improved and refined in our subsequent researches. Generally, the system function is comparatively complete with stable and reliable running, simple operation and convenient maintenance.

This system has the following highlights:

(1) With the B/S method, students can learn any time at any place. Unlimited by region and time, students can access to the Internet and open the browser to learn without installing a client, no matter you are on business trip, go out or are travelling.

(2) It has no any requirements for hardware of student client.

(3) An E-business module is built in the system, making it simple and easy for students to pay tuition fees.

\section{Acknowledgments}

This research is supported by Guangdong Province Outstanding Young Teachers Training program Funded Project (Grant No. 2015S02 - Jianfeng Luo). the Guangdong Science and Technology Department of High Tech Industrialization Project (Grant No. 2012B010100050 - Jianfeng Luo) and the Special 
Funds for Demonstration Projects of Dongguan Polytechnic College (Grant No. ZXHQ2014d001 Jianfeng Luo). Educational research subject (professional education category) of Education Research Institute of Guangdong Province(project number: GDJY2015Bb060- Shanshan Ji)

\section{References}

1. Liu Yanling. Improve Computer Classroom Effect by Using Network Technology. Modern Aggregation. 2009, (2)

2. Zhang Yueting and $\mathrm{Gu}$ Yanling. ASP.NET Step by Step. Tsinghua University Press. 2008

3. Translated by Li Minbo. C\# Advanced Programming. Tsinghua University Press, 2006, (1)
4. Wang Fengmao and Guo Shuyan. SQL Server 2000 Practical Development Tutorial. China Electric Power Press. 2006

5. Dong Jing. Design and Realization of ASP.NET-based Alumni Record System. China Science and Technology Information, 2011, (3)

6. $\mathrm{Wu}$ Ping, Liu Yimin and Chen Heping. Unreadable Codes of ASP.NET Cross-page Value-passing and Solution. Information Science, 2011, (5)

7. Translated by $\mathrm{Li}$ Minbo. C\# Advanced Programming. Tsinghua University Press, 2006, (1) 